\author{
Ezgi Erkiliç̧, Elvin Kesimci, Cihan \\ Döğer, Tülin Gümüş, Abdullah Yalçin \\ and Orhan Kanbak \\ Anesthesiology and Reanimation Department, \\ Ataturk Training and Research Hospital, Ankara, \\ Turkey \\ Dates: Received: 27 January, 2015; Accepted: 16 \\ March, 2015; Published: 18 March, 2015 \\ *Corresponding author: Ezgi Erkılıc, MD, \\ Consultant of Anesthesia, Anesthesiology and \\ Reanimation Department, Ataturk Training and \\ Research Hospital, Ankara, Turkey, E-mail: \\ eerkilic72@yahoo.com \\ www.peertechz.com \\ ISSN: 2455-3476 \\ Keywords: Endovascular surgery; Anesthesia
}

\section{Research Article \\ Anesthetic Management and Perioperative Complications in Endovascular Interventions: The Turkish Experience}

\section{Introduction}

Abdominal and thoracic aortic aneurysms (AAA and TAA) are major common health problems in men over the age of 65 in developed countries [1]. The age-related increase in the incidence of AAA and TAAA makesmore difficult the intervention due to high rate ofcomorbidities [2-4]. Open repair is associated with high operative morbidity. On the other hand, some authors reported a mortality rate less than $5 \%$ and prolonged hospital stay in well organized centers, even in ruptured aneurysms the results did not differ significantly [5-8]. EVAR is a minimally invasive and an alternative treatment technique compared with traditional open surgery. By this way, hemodynamic fluctuations and endocrine stress response are lessened and cardiac and pulmonary complications are rare [9-12]. These advantages accelerate the weaning period [13]. An anesthesiologist plays an essential role for these patients. For successful anesthetic management in these patients, it is important to select the best approach with an understanding of the patient's health status and choices.

This paper evaluates the perioperative anesthetic experiences for a consecutive series of patients who underwent endovascular abdominal and thoracalaneurysm repair in our institution within a 5 -year period.

\section{Materials and Methods}

Between 2009 and 2014, EVAR and TEVAR procedures were performed in one hundred and twenty symptomatic but unrupturedpatientsat Ankara Atatürk Education and Research Hospital. We analysed the data of these patients with regard to anesthetic issues. The Institutional ethics committee approved the study and informed consent was obtained from all patients.Patients were evaluated preoperatively. Routine anesthetic preprocedural evaluation focused on cardiovascular parameters, airway control, and other systemic dysfunctions. No premedication was given. Clinical data of patients, parameters for process, duration of intensive care unit and hospital stay up to discharge time were recorded. All procedures were performed in the interventional radiology unit in our hospital due to lack of hybrid operating room. After inserting an intravenous(IV) catheter into a large arm vein, standard monitoring was applied. In addition to standard monitoring, invasive arterial 
blood pressure monitoring, urinary catheterization were performed in every patient. Decision of central venous catheterization was left to the anesthesiologist.Depending on the procedure some patients had cerebrospinal fluid (CSF) drainage. At the beginning of the procedure, we administered heparin $5000 \mathrm{U}$ IV to achieve an activated coagulation time (ACT) measurement in the level twice as high of normal. Local anesthetic infiltration, consisting of 10$20 \mathrm{ml}$ of $1 \%$ lidocaine was applied to the groin. General anesthesia (GA), or regional anesthesia(RA), or sedoanalgesia was preferred according to the anesthesiologist's decision. Different agents were used to provide anesthesia. The patients who underwent GA were orally intubated. Either sevoflurane (0.8\%-1.1\% minimum alveolar concentration) in an oxygen air mixture at $\mathrm{FiO}_{2}$ of $50 \%$ combined with remifentanilinfusio(0.02-2 $\left.\mu \mathrm{g} \cdot \mathrm{kg}^{-1} \cdot \mathrm{min}^{-1}\right)$ or propofol/remifentanil infusion $\quad\left(3-5 \mathrm{mg} \cdot \mathrm{kg}^{-1} \cdot \mathrm{h}^{-1} / 0.02-2 \mu \mathrm{g} \cdot \mathrm{kg}^{-1} \cdot \mathrm{min}^{-1}\right) \quad$ (total intravenous anesthesia technique) were used for maintenance of anesthesia. We aimed to keep the mean arterial pressure above $90 \mathrm{mmHg}$ and systolic blood pressure less than $140 \mathrm{mmHg}$ to prevent complications due to rupture and ischemia during the procedurein accordance with the literature [14]. To achieve this goal, hypovolemia, if present, was corrected by rapid volume expansioninitially. Hemodynamic data and target arterial pressure values determined the use of vasoactive and / or inotropic agents. The aim was to provide adequate coronary perfusion for normal systemic blood pressure avoiding tachycardia. When preload and contractility were evaluated as optimal, bolus ephedrine (5mg), or continuous epinephrine, and/or norepinephrine (0.03-0.06 $\left.\mu \mathrm{g} . \mathrm{kg}^{-1} \cdot \mathrm{min}^{-1}\right)$ infusions were used to correct arterial hypotension. Thus dopamine infusion was started as required.

Standard surgical techniques were applied to all patients. Either suprarenal or infrarenal fixation was used. For TEVAR patients, chimneystents were placed. In only 3 patients a two-by-two chimneyand-periscope technique was performed. The femoral access was obtained with micropuncture, and access angiogram was obtained via microcatheter before dilating the tract. After the procedure, completion angiography was performed in allcases to confirm satisfactory aneurysm exclusion. At the end of the procedure, catheters were removed and femoral access sites were sealed by tightening the preplaced closing sutures.

Infusion of intravenous nitroglycerin was performed when hypertension (rising more than $25 \%$ control value of intraoperative systolic blood pressure or rising above $140 \mathrm{mmHg}$ ) occured during operation. All vasoactive drugs were made available in perfusors during operation. Clinical neurological assessment of the patients were made by checking consciousness, speech, muscle strength and motor movements in patients who did not have GA. Patients receiving GA were preferred to be extubated in Cardiovascular Surgery Intensive Care unit; because of the long distance between the two units.

\section{Statistical Analysis}

Data analysis was performed in SPSS for Windows 15.0 packet programed. It was investigated by Smirnow Test whether the distribution of numerical variables were conformed with normal distribution. Descriptive statistics were shown as mean \pm standart deviation or median (minimum-maximum) for numeric variables and as the number of cases and (\%) for categorical variables. OneWay ANOVA test was used in determination of numeric data conforming normal distribution in independent groups. In case of differences occurbetween groups, Tukey test was used as Post-Hoc test in order to determine from which group differences occured. Kruskal-Wallis test was used for not normally distrubeted data. Bonferroni correction and Mann-Whitney $\mathrm{U}$ test in groups were performedin case differences occur between groups. Categorical variables were assessed by Chi-Square. Results were considered statistically significant for $\mathrm{p}<0,05$.

\section{Results}

A total of 120 endovascular stent graft patients were evaluated in this study(19 females, 101 males). Patient's demographic data are shown in Table 1. The mean age of the patients was $70 \pm 11$ in EVAR group, and it was $63 \pm 11$ in TEVAR group, while it was $60 \pm 16 \mathrm{in}$ the group having both EVAR-TEVAR in one stage. The percentage of male sex was significantly higher( $\mathrm{p}=0,007)$. The distribution of ASA class among EVAR, TEVAR and EVAR-TEVAR patients did not differ (Table 1). The $18.5 \%$ of patients in EVAR and $23.5 \%$ of patients in TEVAR group were emergency cases but not ruptured. Invasive arterial monitoring was applied to all patients. Central venous catheterization was not performed in 35patients in EVAR group and8 patients in TEVAR group. Anesthesia and surgery duration, the need for blood transfusion and inotropic and vasodilator agents in EVAR and TEVAR groups were similar (Table 2).

In EVAR cases, $79 \%$ of patients had general anesthesia (GA). This incidence was $93.9 \%$ in TEVAR patients. Only 1 patient in EVAR group and 1 patient in EVAR-TEVAR group was able to cooperate with the anesthesiologist to have sedoanalgesia. The two patients having insufficient spinal anesthesia had GA afterwards. Unfortunately, one of these patients died because of hemodynamic instability due to bleeding, during open surgery. CSF drainage catheterization and intracranial pressure monitoring were performed in $18 \%$ of patients of TEVAR patients before the procedure.

Length of stay in ICU was 1 day in EVAR patients and 2 days in TEVAR ones.

After the procedure, 5 patients in EVAR group, 1 patient in TEVAR group, and 1 patient in EVAR-TEVAR group died in the first 5 days due to complications related to respiratory and renal insufficiencies. 30 day mortality could not be followed because of lack of communication between patients and clinicians.

\section{Discussion}

Nowadays, less invasive interventions may be more advantageous in patient populations of older age with higher mortality rates than open surgery due to cardiovascular comorbidities associated. Endovascular interventions for AAA provide protection from damage caused by surgical stress of a major surgery. Thus, perioperative complications, morbidity and mortality are decreased $[15,16]$.

Anesthetic technique in high risk patients undergoing endovascular interventions is very important. Taking into account that these patients will have more advantages from less invasive approach, it is also stated that they will benefit from less invasive 
Table 1: Demographic characteristics of patients.

\begin{tabular}{|c|c|c|c|c|c|}
\hline & & EVAR & TEVAR & EVAR+TEVAR & \multirow{2}{*}{ p } \\
\hline & & $(n=81)$ & $(n=34)$ & $(n=5)$ & \\
\hline \multicolumn{2}{|l|}{ Age (year) } & $69.94 \pm 10.94$ & $63.24 \pm 11.20$ & $60.20 \pm 15.87$ & $0.006^{*}$ \\
\hline \multirow{2}{*}{ Gender } & Male & $74(91.4 \%)$ & $24(70.6 \%)$ & $3(60.0 \%)$ & \multirow{2}{*}{$0.007^{*}$} \\
\hline & Woman & $7(8.6 \%)$ & $10(29.4 \%)$ & $2(40.0 \%)$ & \\
\hline \multicolumn{2}{|l|}{ Height (cm) } & $170(146-195)$ & $169.5(150-180)$ & $166(160-175)$ & 0.682 \\
\hline \multicolumn{2}{|l|}{ Weight (kg) } & $76.81 \pm 15.96$ & $80.09 \pm 12.81$ & $81.60 \pm 5.64$ & 0.481 \\
\hline \multicolumn{2}{|l|}{ BMI $\left(\mathrm{kg} / \mathrm{m}^{2}\right)$} & $27.22 \pm 4.96$ & $29.09 \pm 5.41$ & $29.58 \pm 2.17$ & \\
\hline \multirow{4}{*}{ ASA } & ASA II & $24(29.6 \%)$ & $13(38.2 \%)$ & $1(20.0 \%)$ & \multirow{4}{*}{0.795} \\
\hline & ASA III & $41(50.6 \%)$ & $14(41.2 \%)$ & $3(60.0 \%)$ & \\
\hline & ASA IV & $14(17.3 \%)$ & $7(20.6 \%)$ & $1(20.0 \%)$ & \\
\hline & ASA V & $2(2.5 \%)$ & $0(0.0 \%)$ & $0(0.0 \%)$ & \\
\hline \multicolumn{2}{|l|}{ EF (\%) } & $60(20-65)$ & $65(50-65)$ & $65(45-65)$ & 0.310 \\
\hline \multirow{2}{*}{ CAD } & No & $47(58.0 \%)$ & $27(79.4 \%)$ & $3(60.0 \%)$ & \multirow{2}{*}{0.091} \\
\hline & Yes & $34(42.0 \%)$ & $7(20.6 \%)$ & $2(40.0 \%)$ & \\
\hline \multirow{2}{*}{ HT } & No & $24(29.6 \%)$ & $5(14.7 \%)$ & $0(0.0 \%)$ & \multirow{2}{*}{0.053} \\
\hline & Yes & $57(70.4 \%)$ & $29(85.3 \%)$ & $5(100.0 \%)$ & \\
\hline \multirow{2}{*}{ DM } & No & 72(88.9\%) & $29(85.3 \%)$ & $4(80.0 \%)$ & \multirow{2}{*}{0.759} \\
\hline & Yes & $9(11.1 \%)$ & $5(14.7 \%)$ & $1(20.0 \%)$ & \\
\hline \multirow{2}{*}{ COPD } & No & $53(65.4 \%)$ & $26(76.5 \%)$ & $3(60.0 \%)$ & \multirow{2}{*}{0.469} \\
\hline & Yes & $28(34.6 \%)$ & $8(23.5 \%)$ & $2(40.0 \%)$ & \\
\hline \multirow{2}{*}{ RF } & No & 72(88.9\%) & $32(94.1 \%)$ & $5(100.0 \%)$ & \multirow{2}{*}{0.519} \\
\hline & Yes & $9(11.1 \%)$ & $2(5.9 \%)$ & $0(0.0 \%)$ & \\
\hline \multirow{2}{*}{ CVE } & No & 78(96.3\%) & $30(88.2 \%)$ & $4(80.0 \%)$ & \multirow{2}{*}{0.175} \\
\hline & Yes & $3(3.7 \%)$ & $4(11.8 \%)$ & $1(20.0 \%)$ & \\
\hline
\end{tabular}

BMI: Body mass index. EF: ejection fraction. CAD: Coronary Artery Disease. COPD: Chronic obstructive pulmonary disease. RF: Renal Failure. CVE: Cerebrovascular event.

Categorical values are shown as $\mathrm{n}(\%)$.

Values with measurable normal distribution are shown as 'Mean \pm Std Deviation'.

Values not showing normal distribution are shown as 'Median (Minimum-Maximum)'.

anesthesia techniques. Anesthetic techniquevary depending on the experience of the surgicalteam, the preferred approach for the intervention, the patient's medical history and accompanying hemodynamic problems [17-19].

Many studies have indicated that, the type of anesthesia was not a determinant [20-22] factor for cardiovascular complications inpatients. Thus; both GA and RA as well as local anesthesia and sedation (LAS) can be applied in endovascular procedures. Some studies do not take into account anesthesia as a factor in determining the result of surgical intervention $[9,15]$. However, anesthesiologists and intensive care specialists are responsible for the successful outcome of these patients. GA is still a popular anesthetic approach [23]. It is preferred in cases expected to have longer durations. While placing the graft, sometimes sessation of breathing is required [19]. At the same time comfort provided by GA is important for a nonexperienced team.

The first series applying local anesthesia by midazolam and propofol infusions in EVAR is a study of 47 patients. In this study $30 \%$ of patients were ASA IV. The duration of procedure was 170 minutes, estimated blood loss was $620 \mathrm{ml}$. In only one patient, general anesthesia was required because of the injury in iliac artery. All patients were mobilized after 24 hours. The length of hospital stay was 2.1 days.
In the first 30 days, noncardiopulmonary complications developed in only 3 patients [24]. Cao et al., performed epidural anesthesia for $54 \%$ of 61 patients undergoing elective EVAR. The decision for anesthetic technique was left to the anesthesiologist in this patient population with an ASA score of III in 75\%. They used midazolam for sedation in regional anesthesia group; so as to keep Ramsey sedation scale as 2. There was no significant difference between GA and RA, in terms of length of stay in ICU; however; the ones in RA group required less ICU referral [25]. Bettex et al., evaluated 91 patients, retrospectively. In contrast to Cao et al., the requirement for ICU stay in GA group was less than RA and LAS groups. However, the length of stay in hospital was significantly shorter in LAS group. The use of inotropes and crystalloids and duration of the procedure were also significantly less [26]. This contradictory results are interesting; but could be attributed to the experiences of the team, and characteristics of patient population. Similarly, in another study, significantly shorter duration of ICU stay (1.9 days) was observed in GA group, together with shorter duration of anesthesia, procedure and less IV fluid infusions. Thus, the authors stated that; patient's co-morbidities were more important than anesthesia technique in determination of the progress in these patients [21].

Verhoeven et al., recognized that respiratory complications were much more and duration of the procedure was longer in EVAR patients 
Table 2: Comparison of groups in terms of perioperative characteristics.

\begin{tabular}{|c|c|c|c|c|c|}
\hline & & EVAR & TEVAR & EVAR+TEVAR & \multirow{2}{*}{$\mathbf{p}$} \\
\hline & & $(n=81)$ & $(n=34)$ & $(n=5)$ & \\
\hline \multirow{2}{*}{ Emergency/Elective } & Emergency & $15(18.5 \%)$ & $8(23.5 \%)$ & $0(0.0 \%)$ & \multirow{2}{*}{-} \\
\hline & Elective & $66(81.5 \%)$ & $26(76.5 \%)$ & $5(100.0 \%)$ & \\
\hline \multirow{5}{*}{ Type of anesthesia } & General & $64(79.0 \%)$ & $31(93.9 \%)$ & $4(80.0 \%)$ & \multirow{5}{*}{-} \\
\hline & Spinal & $13(16.0 \%)$ & $1(3.0 \%)$ & $0(0.0 \%)$ & \\
\hline & Sedation & $1(1.2 \%)$ & $0(0.0 \%)$ & $1(20.0 \%)$ & \\
\hline & Spinal+General & $2(2.5 \%)$ & $0(0.0 \%)$ & $0(0.0 \%)$ & \\
\hline & Epidural+general & $1(1.2 \%)$ & $1(3.0 \%)$ & $0(0.0 \%)$ & \\
\hline \multirow{4}{*}{ Central catheter location } & No & $35(43.2 \%)$ & $8(23.5 \%)$ & $1(20.0 \%)$ & \multirow{4}{*}{-} \\
\hline & Right Jugular & $44(54.3 \%)$ & $25(73.5 \%)$ & $4(80.0 \%)$ & \\
\hline & Left Jugular & $2(2.5 \%)$ & $0(0.0 \%)$ & $0(0.0 \%)$ & \\
\hline & Left Femoral & $0(0.0 \%)$ & $1(2.9 \%)$ & $0(0.0 \%)$ & \\
\hline \multirow{5}{*}{ Artery cannulation } & Right Radial & $71(87.7 \%)$ & $29(85.3 \%)$ & $3(60.0 \%)$ & \multirow{5}{*}{-} \\
\hline & Left Radial & $2(2.5 \%)$ & $0(0.0 \%)$ & $0(0.0 \%)$ & \\
\hline & Right brachial & $7(8.6 \%)$ & $5(14.7 \%)$ & $1(20.0 \%)$ & \\
\hline & Left brachial & $1(1.2 \%)$ & $0(0.0 \%)$ & $0(0.0 \%)$ & \\
\hline & Left femoral & $0(0.0 \%)$ & $0(0.0 \%)$ & $1(20.0 \%)$ & \\
\hline \multicolumn{2}{|l|}{ Anesthesia time (Min) } & $165(75-750)$ & $165(75-460)$ & $210(110-675)$ & 0.744 \\
\hline \multicolumn{2}{|l|}{ Surgical time (Min) } & $135(45-720)$ & $135(60-420)$ & $190(95-630)$ & 0.625 \\
\hline \multirow{2}{*}{ Transfusion } & Yes & $63(77.8 \%)$ & $27(79.4 \%)$ & $2(40.0 \%)$ & \multirow{2}{*}{0.195} \\
\hline & No & $18(22.2 \%)$ & $7(20.6 \%)$ & $3(60.0 \%)$ & \\
\hline \multicolumn{2}{|l|}{ Erythrocyte transfusion (u) } & $1(1-8)$ & $1.5(1-4)$ & $2(1-3)$ & 0.788 \\
\hline \multirow{2}{*}{ Inotropic Agent } & No & $66(81.5 \%)$ & $29(85.3 \%)$ & $5(100.0 \%)$ & \multirow{2}{*}{0.524} \\
\hline & Yes & $15(18.5 \%)$ & $5(14.7 \%)$ & $0(0.0 \%)$ & \\
\hline \multirow{2}{*}{ Using of vasadilator agent } & No & $64(79.0 \%)$ & $24(70.6 \%)$ & $4(80.0 \%)$ & \multirow{2}{*}{0.621} \\
\hline & Yes & $17(21.0 \%)$ & $10(29.4 \%)$ & $1(20.0 \%)$ & \\
\hline
\end{tabular}

Categorical values are shown as $\mathrm{n}(\%)$.

Values not showing normal distribution are shown as 'Median (Minimum-Maximum)'

undergoing GA [27]. Wax et al., had a high percentage of patients undergoing EVAR with regional anesthesia. The different anesthesia groups differed from each other in only length of stay at hospital [18]. In a series of 5557 EVAR cases, the increase in duration of procedure, ICU admission and systemic complications were associated with GA [23]. Thus, GA was found to be an independent risk factor for mortality following endovascular procedures [28]. Bakker et al., stated that postprocedural mortality and renal complications in the following 30 days after EVAR were increased in the patienst having GA. This was thus, correlated with longer durations of hospital stay [13]. In two other larger series of endovascular interventions, similar results were reported $[23,29]$. At our institution, we preferred general anesthesia with tracheal intubation, especially at the beginning of the procedures. We switched to the use of regional anesthesia or local anesthesia and sedation following an assumed learning curve and experiences of the team. For induction of anesthesia, we used thiopental sodium, etomidate or propofol. A balanced technique, composed of sevoflurane combined with remifentanil or propofol/ remifentanil infusion, was used during maintenance. This anesthetic practice allowed rapid recovery in the elderly patients. According to our protocol, all patients were transferred to the ICU at the end of the procedure. The long distance between radiology unit and ICU made us concerned about the safety of airway and hemodynamic parameters during the transport of the patients. $29 \%$ of patients required inotropic support. However, duration of anesthesia, procedure, blood transfusion requirement, and inotropic agent usage were similar between EVAR and TEVAR patients. The type of anesthesia did not make a difference in the length of stay in ICU. Five patients having GA for EVAR had early mortality in ICU.

One of the most important complication of TEVAR is SCI (Spinal cord ischemia).This is a multifactorial pathology and not clearly understood [30-32]. There is not a consensus about the application of CSF among the authors, however, it is mostly advised in chosen patients for this procedure [14]. We also had CSF drainage in some of TEVAR patients. This decision was made according to the opinions of surgeons and anesthesiologists. The seven patients having CSF drainage did not have any neurological problems after the procedure. In a series of 139 TEVAR patients, 30 day mortality rate was $1.5 \%$ 
and the incidence of SCIwas 3\% [33]. In another study of 13 patients, no complication like stroke was reported [34]. One of the suggested opinions in the prevention of complications, are avoidance of hypotension and keeping mean arterial pressure $\geq 90 \mathrm{mmHg}$. Besides, volume status of the patient is important [14].

In our study, anesthesia method was not randomized. As in other studies, according to the decision of anesthesiologist, the type of anesthesia and the pharmacological agents used are different. Similar to the other authors; we believe that anesthesia techniques and agents are not associated with major postprocedural complications. Regarding our results, we observed the importance of experience for improved clinical results. Future studies in regard to anesthesia are required in this field, and as anesthesiologists, we must be aware of the entire procedure and several other factors for the patient's safety.

\section{References}

1. Sakalihasan N, Limet R, Defawe OD (2005)Abdominal aortic aneurysm. Lancet 365: 1577-1589.

2. Bengtsson H, Bergqvist D, Sternby NH (1992) Increasing prevalence of abdominal aortic aneurysms. A necropsy study. Eur J Surg158:19-23.

3. Bickerstaff LK, Hollier LH, Van Peenen HJ, Melton LJ 3rd, Pairolero PC, et al (1984) Abdominal aortic aneurysms: the changing natural history. J VascSurg $1: 6-12$.

4. Melton LJ 3rd, Bickerstaff LK, Hollier LH, Van Peenen HJ, Lie JT, et al. (1984) Changing incidence of abdominal aortic aneurysms: a population-based study. Am J Epidemiol120:379-386.

5. Reimerink JJ, Hoornweg LL, Vahl AC, Wisselink W, van den Broek TA, et al. (2013) Endovascular repair versus open repair of ruptured abdominal aortic aneurysms: a multicenter randomized controlled trial. Ann Surg 258: 248256.

6. Van Beek SC, Conijn AP, Koelemay MJ, Balm R (2014) Editor's Choice Endovascular aneurysm repair versus open repair for patients with a ruptured abdominal aortic aneurysm: a systematic review and meta-analysis of shortterm survival. Eur J VascEndovascSurg 47: 593-602.

7. Blankensteijn JD, Lindenburg FP, Van der Graaf Y, Eikelboom BC (1998) Influence of study design on reported mortality and morbidity rates after abdominal aortic aneurysm repair. Br J Surg 85:1624-1630.

8. Dardik A, Lin JW, Gordon TA, Williams GM, Perler BA (1999) Results of elective abdominal aortic aneurysm repair in the 1990s: A population-based analysis of 2335 cases. J VascSurg 30:985-995.

9. Greenhalgh RM, Brown LC, Kwong GP, Powell JT, Thompson SG (2004) EVAR trial participants. Comparison of endovascular aneurysm repair with open repair in patients with abdominal aortic aneurysm (EVAR trial 1), 30-day operative mortality results: randomised controlled trial.Lancet364:843-848.

10. Schouten O, van Waning VH, Kertai MD, Feringa HH, Bax JJ, et al. (2005) Perioperative and long-term cardiovascular outcomes in patients undergoing endovascular treatment compared with open vascular surgery for abdominal aortic aneurysm or iliaco-femoro-popliteal bypass. Am J Cardiol96:861-866.

11. Bertges DJ, Goodney PP, Zhao Y, Schanzer A, Nolan BW, et al.(2010) Vascular Study Group of New England. The Vascular Study Group of New England Cardiac Risk Index (VSG-CRI) predicts cardiac complications more accurately than the Revised Cardiac Risk Index in vascular surgery patients. J VascSurg52:674-683

12. Barry MC, Hendriks JM, van Dijk LC, Pattynama P, Poldermans D, et al (2010)A comparative study of myocardial injury during conventional and endovascular aortic aneurysm repair: measurement of cardiac troponin $\mathrm{T}$ and plasma cytokine release. Ir J Med Sci179:35-42.

13. Bakker EJ, van de Luijtgaarden KM, van Lier F, Valentijn TM, Hoeks SE, et al. (2012) General anaesthesia is associated with adverse cardiac outcome after endovascular aneurysm repair. Eur J VascEndovascSurg 44:121-125.

14. Ullery BW, Wang GJ, Low D, Cheung AT (2011) Neurological complications of thoracic endovascular aortic repair. SeminCardiothoracVascAnesth 15:123-140.

15. Lee WA, Carter JW, Upchurch G, Seeger JM, Huber TS (2004) Perioperative outcomes after open and endovascular repair of intact abdominal aortic aneurysms in the United States during 2001. J VascSurg 39:491-496.

16. Kahn RA, Moskowitz DM, Manspeizer HE, Reich DL, McConville JC, et al. (1999) Endovascular aortic repair is associated with greater hemodynamic stability compared with open aortic reconstruction. J CardiothoracVascAnesth13:42-46.

17. Walschot LH, Laheij RJ, Verbeek AL (2002) Outcome after endovascular abdominal aortic aneurysm repair: a meta-analysis. J EndovascTher9:82-89.

18. Wax DB, Garcia C, Campbell N, Marin ML, Neustein S (2010) Anesthetic experience with endovascular aortic aneurysm repair. Vasc Endovascular Surg 44:279-281.

19. Wylie SJ, Wong GT, Chan YC, Irwin MG (2012) Endovascular aneurysm repair: a perioperative perspective. ActaAnaesthesiolScand56:941-949.

20. Parra JR, Crabtree T, McLafferty RB, Ayerdi J, Gruneiro LA, et al. (2005) Anesthesia technique and outcomes of endovascular aneurysm repair. Ann VascSurg19:123-129.

21. De Virgilio C, Romero L, Donayre C, Meek K, Lewis RJ, et al. (2002) Endovascular abdominal aortic aneurysm repair with general versus local anesthesia: a comparison of cardiopulmonary morbidity and mortality rates. $J$ VascSurg36:988-991.

22. Verhoeven EL, Cinà CS, Tielliu IF, Zeebregts CJ, Prins TR, et al. (2005) Local anesthesia for endovascular abdominal aortic aneurysm repair.J VascSurg42:402-409.

23. Ruppert V, Leurs LJ, Steckmeier B, Buth J, Umscheid T (2006) Influence of anesthesia type on outcome after endovascular aortic aneurysm repair: an analysis based on EUROSTAR data. J VascSurg44:16-21.

24. Henretta JP, Hodgson KJ, Mattos MA, Karch LA, Hurlbert SN, et al. (1999) Feasibility of endovascular repair of abdominal aortic aneurysms with local anesthesia with intravenous sedation.JVascSurg29:793-798.

25. Cao P, Zannetti S, Parlani G, Verzini F, Caporali S, et al.(1999) Epidural anesthesia reduces length of hospitalization after endoluminal abdominal aortic aneurysm repair. J VascSurg 30:651-657.

26. Bettex DA, Lachat M, Pfammatter T, Schmidlin D, Turina MI, et al. (2001) To compare general, epidural and local anaesthesia for endovascular aneurysm repair (EVAR). Eur J VascEndovascSurg21:179-184.

27. Verhoeven EL, Cinà CS, Tielliu IF, Zeebregts CJ, Prins TR, et al. (2005) Local anesthesia for endovascular abdominal aortic aneurysm repair. J VascSurg42:402-409.

28. Walschot LH, Laheij RJ, Verbeek AL (2002) Outcome after endovascular abdominal aortic aneurysm repair: a meta-analysis. J EndovascTher 9:82-89.

29. Edwards MS, Andrews JS, Edwards AF, Ghanami RJ, Corriere MA, et al. (2011) Results of endovascular aortic aneurysm repair with general, regional, and local/monitored anesthesia care in the American College of Surgeons National Surgical Quality Improvement Program database. J VascSurg 54:1273-1282.

30. Greenberg RK, Lu Q, Roselli EE, Svensson LG, Moon MC, et al. (2008) Circulation. Contemporary analysis of descending thoracic and thoracoabdominal aneurysm repair: a comparison of endovascular and open techniques. 118:808-817.

31. Feezor RJ, Martin TD, Hess PJ, Klodell CT, Beaver TM, et al. (2007) Risk factors for perioperative stroke during thoracic endovascular aortic repairs (TEVAR). J EndovascTher 14:568-573.

32. Chang CK, Chuter TA, Reilly LM, Ota MK, Furtado A, et al. (2008) Spinal 
arterial anatomy and risk factors for lower extremity weakness following endovascular thoracoabdominal aortic aneurysm repair with branched stentgrafts. J EndovascTher15:356-362.

33. Makaroun MS, Dillavou ED, Kee ST, Sicard G, Chaikof E, et al. (2005) Endovascular treatment of thoracic aortic aneurysms: results of the phase II multicenter trial of the GORE TAG thoracic endoprosthesis. J VascSurg 41:1-

34. Dake MD, Miller DC, Semba CP, Mitchell RS, Walker PJ, et al. (1994) Transluminal placement of endovascular stent-grafts for the treatment of descending thoracic aortic aneurysms. N Engl J Med 331:1729-1734.

Copyright: @ 2015 Erkiliç E, et al. This is an open-access article distributed under the terms of the Creative Commons Attribution License, which permits unrestricted use, distribution, and reproduction in any medium, provided the original author and source are credited.

Citation: Erkiliç E, Kesimci E, Döğer C, Gümüş T, Yalçin A, et al. (2015) Anesthetic Management and Perioperative Complications in Endovascular 